\title{
Detection Limit
}

National Cancer Institute

\section{Source}

National Cancer Institute. Detection Limit. NCI Thesaurus. Code C105701.

The smallest concentration of an analyte that can be determined with a stated precision or confidence. 